\title{
Justification of the requirements for an environmentally safety mobile power unit of class 1.4-2.0
}

\author{
Alexander Lavrov* \\ Federal Scientific Agro-Engineering Center VIM, 1 Institutsky proezd, 5, Moscow, 109428, Russia
}

\begin{abstract}
The systematic analysis of world trends in the development of production and sale of agricultural tractors has shown that advertising and exhibition trends of overstating the power and saturation of tractors with automation elements for Russia are technologically outdated. It is proposed to consider increasing energy efficiency and ensuring their environmental safety in the full life cycle as the main indicators of the competitiveness of agricultural tractors in the world market.
\end{abstract}

\section{Introduction}

The state of the Russian tractor industry is characterized by deep restructuring processes. In this regard, it becomes relevant to choose a long-term direction for the development of technical policy, ensuring the competitiveness of domestic tractor equipment [1-4].

A block-modular frame arrangement, a replaceable wheel-caterpillar propeller with increased traction and coupling characteristics, an automated electric drive and other innovative solutions for the organization of highly standardized tractor production [5-6].

Block-modular frame layout, replaceable wheeled-caterpillar propulsion with increased traction and coupling characteristics, automated electric drive and other innovative solutions that contribute to the organization of highly standardized production of tractors will provide a significant reduction in structural weight, increase productivity and reduce total energy consumption per unit of useful work in $1,4 \ldots 1.6$ times [7].

Universal row-crop tractors of classes 1, 4 and 2 carry out in crop production up to $40 \%$ of the total volume of work, their technological need for the park is about 190 thousand tractors, but they are not produced in Russia.

The developed initial requirements (Fig. 1) implement the concept of accelerated creation of modern standard-size series of off-road traction vehicles based on the use of a progressive element base, which is science-intensive components for general machinebuilding applications.

\footnotetext{
*Corresponding author: vimlavrov@mail.ru
} 


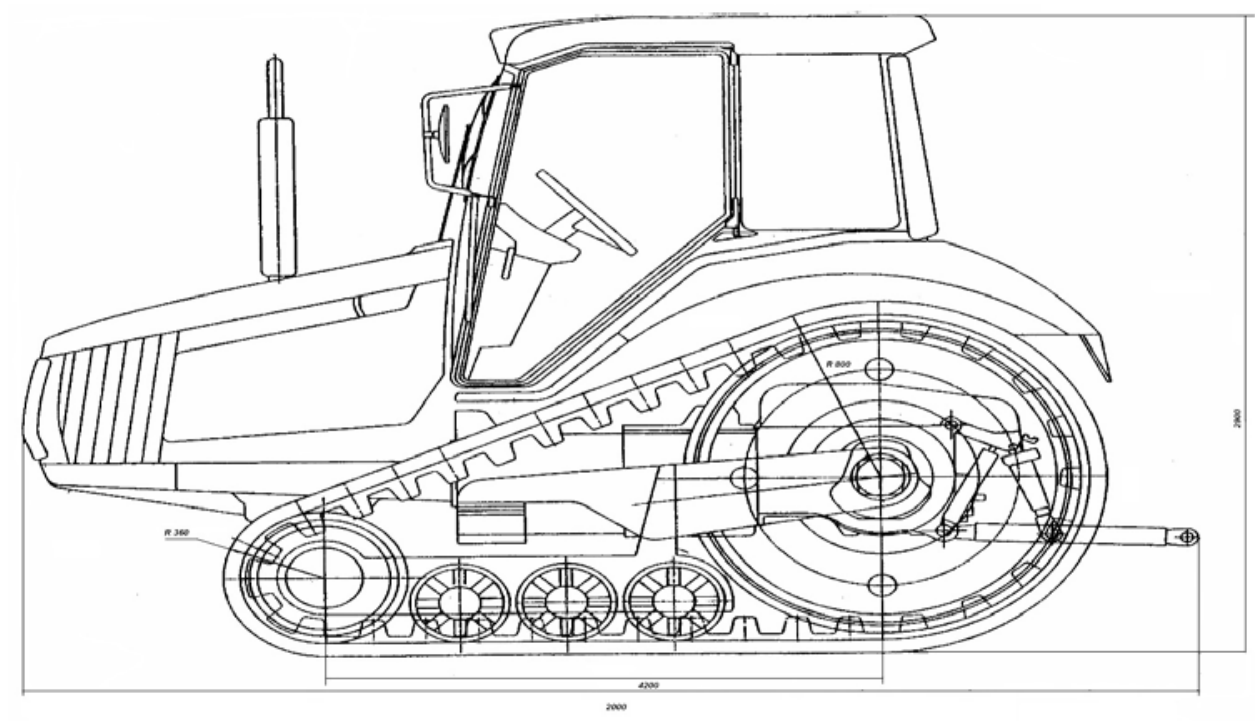

Fig. 1. Environmentally friendly mobile power unit of class 1.4-2.0

The purpose of the work was to substantiate the initial requirements for a mobile power unit of class 1.4-2.0, based on existing developments aimed at improving the environmental safety of agricultural machinery.

\section{Materials and methods}

Advanced domestic research in the field of increasing the efficiency of using engine power in a machine-tractor unit, interaction of running systems with the soil and increasing the environmental safety of individual units and systems made it possible to substantiate the creation of a competitive tractor that surpasses the best foreign models in terms of energy efficiency and environmental safety. The fundamental novelty and usefulness of the proposed solutions are protected by 25 patents of the Russian Federation [8].

4 types of elements of prototypes were manufactured and tested (automatic power take-off systems (Fig. 2) and protection of hydraulic lines from emergency spills (Fig. 3), a battery-free start-up system based on electric energy storage devices (Fig. 4), rubberreinforced RRC caterpillar), the kinematic diagram of a special transmission by I.P. Ksenevich has been calculated, Mechanical transmissions with stepless regulation of gear ratios between replaceable gearbox stages. "Mobile equipment", No. 1, 2004, p. 12-20, a patent was received for the invention "Undercarriage of a caterpillar tractor (Fig. 5).

Tire sizes have been selected that provide protection zones when working in row spacing of 45,60,70,90 $\mathrm{cm}$. (Table 1), an assessment of the admissibility of using the type of tires in accordance with the norms of maximum pressure on the soil in accordance with GOST R 58655-2019 is given. Power take-off system Purpose: drive of the power takeoff shafts of tractors and other traction and transport machines in a continuously variable speed mode with automatic maintenance of a given rotational speed. Principle of operation: automatic regulation of the amount of working fluid supply to the hydraulic motor of the PTS (power take off shaft) shank drive based on the control of its rotation frequency. Execution: block-modular. 


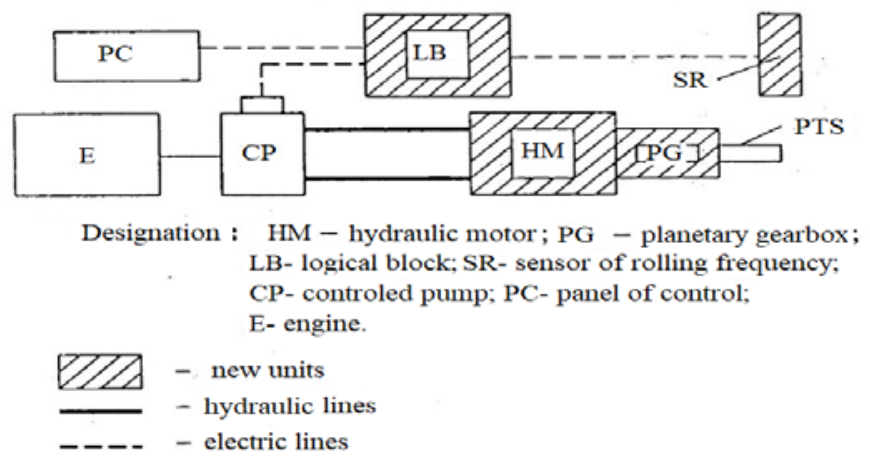

Fig. 2. Power take-off system.

Table 1. Main technical data

\begin{tabular}{|l|c|}
\hline \multicolumn{1}{|c|}{ Indicator } & Value \\
\hline Maximum transmitted power, $\mathrm{kW}$ & $75 ; 100$ \\
\hline $\begin{array}{l}\text { Hydraulic drive pressure, MPa: } \\
\text { - nominal } \\
\text { - maximum }\end{array}$ & 40 \\
& 45 \\
\hline Working volume of the hydraulic motor, cm3 & $33 ; 40$ \\
\hline Operating speed of PTO shank in stepless regulation mode, sec-1 & $8,33 \ldots 20$ \\
\hline $\begin{array}{l}\text { Maximum deviation of the PTS shank rotation frequency from the set } \\
\text { value, } \%\end{array}$ & \pm 5 \\
\hline $\begin{array}{l}\text { Time of supply change in the range from maximum value to zero, C, no } \\
\text { more }\end{array}$ & \\
\hline Weight (hydraulic motor, reducer, electronic unit, speed sensor), kg & 55 \\
\hline
\end{tabular}

The system provides: reduction of fuel consumption by up to $30 \%$ due to the transfer of the engine of the machine with underload to a lower rotational speed of the PTS shank; the ability to work with motors of constant power.

Automatic system of the protection of a hydraulic line

Purpose: prevention of emergency losses of working fluid during depressurization of hydraulic systems of tractors, combines, dump trucks and other mobile machines.

Principle of operation: combined control of the current value of the level of the working fluid in the tank and the pressure in the pressure head line with automatic shutdown of the pump in case of loss of tightness.

Execution: block-modular.

Block scheme of the hydraulic line automatic protection system.

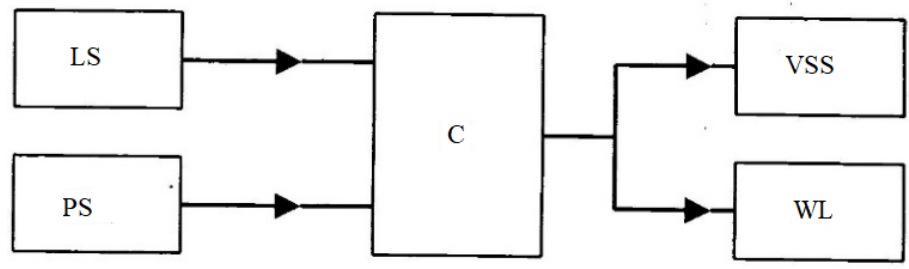

Designation : LS-Level sensor; PS- pressure sensor; C- controller; WL-warning light; VSS- valve switch solenoid.

Fig. 3. Automatic hydraulic line protection system 
Table 2. Main technical data

\begin{tabular}{|l|c|}
\hline \multicolumn{1}{|c|}{ Indicator } & Value \\
\hline $\begin{array}{l}\text { Range of automatic control of the working fluid level in the tank, mm, not } \\
\text { less }\end{array}$ & 100 \\
\hline $\begin{array}{l}\text { Total control range of the working fluid level in the tank (taking into account } \\
\text { the level change in the period between refueling), mm, not less }\end{array}$ & 250 \\
\hline Accuracy of automatic level control, mm, no more & 10 \\
\hline Response time of the pump cut-off system after an alarm occurs, s, no more & 1 \\
\hline Pressure sensor response level, MPa & $\begin{array}{c}2,5+1 \\
\text { (other values - } \\
\text { on request) }\end{array}$ \\
\hline Amount of level sensors & 1 (2- on request) \\
\hline
\end{tabular}

The system provides: reduction of losses of mineral oils by 200 thousand tons per year when equipping tractors, combines and dump trucks of the CIS countries; reduction of equipment downtime; reduction of environmental pollution of the soil.

Starting system for internal combustion engine with energy storage

Purpose: ensuring the start-up of internal combustion engines of mobile ground vehicles from an energy storage device.

Principle of operation: starting of internal combustion engines from an energy storage device, the storage battery is not involved in the process.

Execution: block-modular.

Block diagram of a starting system with an energy storage

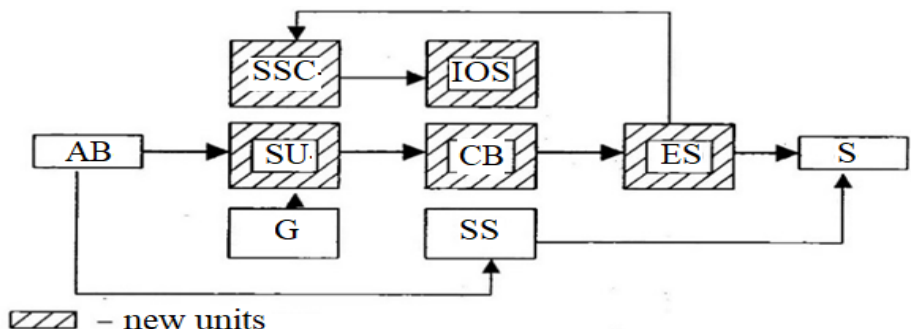

Designation : AB- accumulator battery; SU- switching unit;

CB-charge block and charge current stabilization;

ES-energy storage; S-starter; SSC- starting system

control unit; SS- starter switch; G- generator;

IOS- indication of operation of the starting system.

Fig. 4. Starting system for internal combustion engines with energy storage

Table 3. Main technical data

\begin{tabular}{|l|c|}
\hline \multicolumn{1}{|c|}{ Indicator } & Value \\
\hline Energy storage capacity (NE), F & 1250 \\
\hline Amount of starts (scrolling), up to NE discharge & 10 \\
\hline $\begin{array}{l}\text { Engine crankshaft rotational speed when cranking (at the 3rd } \\
\text { second at a temperature of minus } 20^{\circ} \mathrm{C} \text { ), min-1 }\end{array}$ & 153 \\
\hline $\begin{array}{l}\text { Starting system weight (excluding the weight of the starter and } \\
\text { wires), } \mathrm{kg}\end{array}$ & 15,5 \\
\hline Service life, $\mathrm{m} / \mathrm{h}$, not less & 10000 \\
\hline
\end{tabular}


The system provides:

- environmental safety by reducing the amount of materials that pollute the environment;

- high reliability of starting the internal combustion engine due to the possibility of increasing the voltage supplied to the starter during start-up to the nominal value and quickly restoring the storage capacity after the previous (failed) start attempt;

- the possibility of a significantly larger number (up to 2 times) start attempts;

- the durability of the starting system, which practically coincides with the service life of the machine;

- a significant reduction in weight and dimensions due to the high electrical characteristics of the drives, which change slightly with a decrease in the air temperature.

Tracked tractor suspension scheme with vibroactive vibration damping and platform stabilization (Patent RU 2162629)

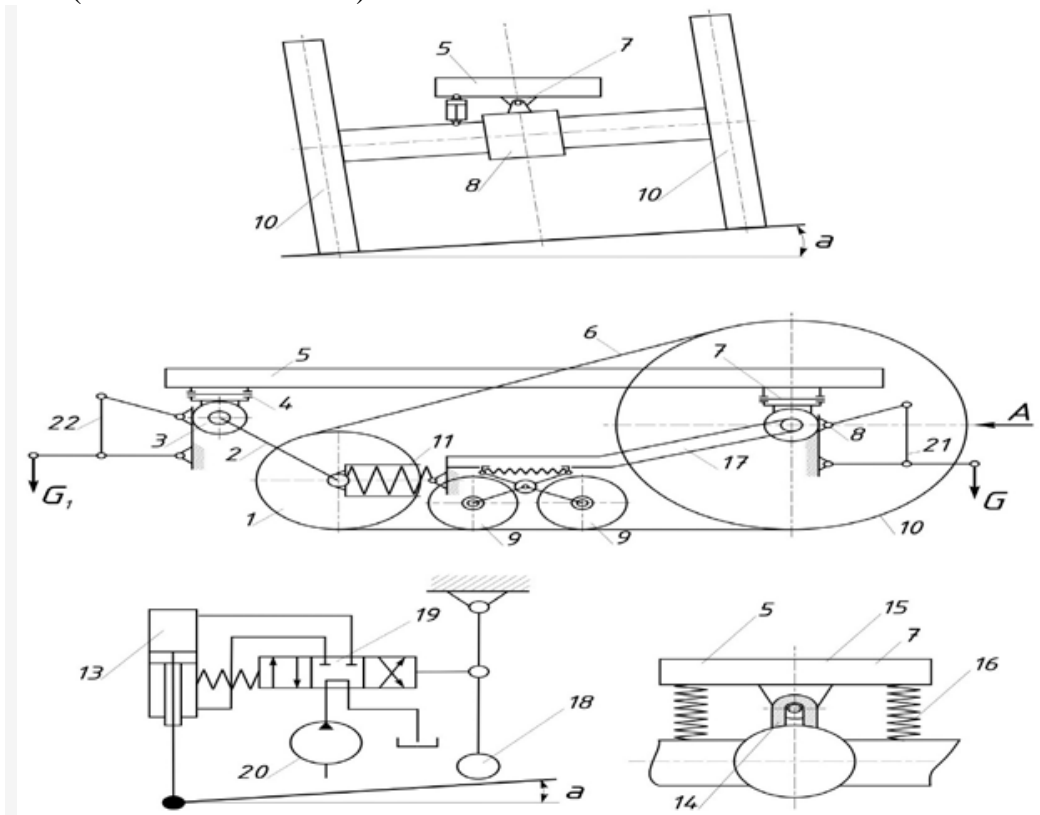

Fig. 5. A schematic representation of a rear view, a side view of the suspension, a view of the rear (driving) axle mating with the frame, and a diagram of the frame position support system. 1 tension wheel, 2 - lever, 3 - beam, 4 and 7 - axles, 5 - frame, 6 - caterpillar, 8 - drive axle, 9 support rollers, 10 - drive wheel, 11 - tensioning mechanism, 13 - power cylinder, 14 - vertical groove, 15 - eyelet, 16 - suspension, 17 - balancer, 18 - vertical sensor, 19 - spool, 20 - pump, 21 rear mechanism of mounted systems, 22 - front mechanism of mounted systems.

\section{Results and Discussions}

The initial requirements for an environmentally friendly mobile energy device of class 1.4-2.0 were developed based on the analysis of the designs of analogues of mobile energy devices existing on the market, and promising directions for the development of their designs, agrotechnical requirements for performing technological operations, various technologies for cultivating crops and economic conditions.

Appointment. Tractors are designed for the cultivation and harvesting of beets, vegetables, potatoes and high-stemmed row crops with row spacing of 45, 60, 70, $90 \mathrm{~cm}$ as part of wide-cut single-operation and combined units, performing general-purpose work, sowing and harvesting grain and other crops, incl. on floodplains, transportation of 
agricultural goods and loading and unloading operations, providing the ability to build flexible quick-coupled technological systems for agricultural purposes.

The main quality indicators are presented in table 4.

Table 4. The main indicators of the quality of the agricultural universal block-modular power plant of traction class 0.6

\begin{tabular}{|c|c|c|}
\hline \multicolumn{3}{|c|}{ General indicators } \\
\hline Traction class & 1,4 & 2 \\
\hline Operational weight, kg & 2800 & 3500 \\
\hline Construction scheme & \multicolumn{2}{|c|}{ frame, block-modular } \\
\hline Operating power of the engine, $\mathrm{kW}$ & 73,5 & 118 \\
\hline \multicolumn{3}{|c|}{ Transmission } \\
\hline Type & \multicolumn{2}{|c|}{ mechanical, step } \\
\hline $\begin{array}{l}\text { Forward speed, km / h: } \\
\text { - technological, } \\
\text { - working, } \\
\text { - transport. }\end{array}$ & \multicolumn{2}{|c|}{$0,1-2,5$} \\
\hline The ratio of adjacent gear ratios & \multicolumn{2}{|c|}{1,33} \\
\hline Efficiency factor & \multicolumn{2}{|c|}{$0,9-0,92$} \\
\hline \multicolumn{3}{|c|}{ Power take-off system. } \\
\hline Location & \multicolumn{2}{|c|}{ front, rear } \\
\hline Type & \multicolumn{2}{|c|}{$\begin{array}{l}\text { mechanical with automatic maintenance of a } \\
\text { given PTS shank rotation frequency. }\end{array}$} \\
\hline Efficiency factor & \multicolumn{2}{|c|}{0,96} \\
\hline \multicolumn{3}{|c|}{ Undercarriage } \\
\hline \multirow[t]{2}{*}{ Mover type } & \multicolumn{2}{|c|}{ exchangeable } \\
\hline & wheeled & caterpillar \\
\hline Maximum pressure on the soil, $\mathrm{kPa}$ & $80-120$ & $50-60$ \\
\hline Conditional traction efficiency & 0,72 & 0,8 \\
\hline Agrotechnical clearance, $\mathrm{m}$ & \multicolumn{2}{|c|}{$\frac{1}{650}$} \\
\hline Track (adjustable), mm & \multicolumn{2}{|c|}{$1400-1800$} \\
\hline
\end{tabular}

Environmental requirements.

The performance of tractors must meet the requirements for the level of impact of running systems on the soil, when working in row spacing of 45, 60, 70 and $90 \mathrm{~cm}$ without restrictions on soil moisture - GOST R 58655-2019.

Economic requirements.

Compared with the tractor "Belarus" 1025, an environmentally friendly mobile power unit of class 1.4, should provide: reduction in crop shortages, centner / ha:

- corn - 8 ... 10;

- sunflower - 3 ... 5 .

Reducing fuel consumption per unit of production, $\mathrm{kg} / \mathrm{c}$ :

- corn - 1.2;

- sunflower - 4.8,

which will allow, taking into account a decrease in the specific material consumption from $50 \mathrm{~kg} / \mathrm{kW}$ ("Belarus" -1025) to $33.3 \mathrm{~kg} / \mathrm{kW}$, to reduce the total energy consumption for performing a unit of useful work by $1.5 \ldots 1.6$ times, subject to environmental safety requirements in the entire range of work performed. The same indicators of the efficiency of the use of an environmentally safe class 2 mobile power unit in comparison with the Belarus 1221 tractor. The technological demand in the park is 90 thousand units (excluding exports).

Requirements for versatility. The number of agricultural machines aggregated in the complex is 370 pcs. 


\section{Conclusions}

The developed initial requirements will be timely and represent the technical level of agricultural tractors developed for the near future. These initial requirements are intended to create energy-efficient agricultural mobile energy facilities based on progressive running systems with increased traction and coupling characteristics, providing, with a significant reduction in structural weight, an environmentally acceptable impact on the soil and a decrease in the total energy intensity of the production of a unit of useful work by 1.5-1.6 times compared to the best samples in the world market.

\section{References}

1. Smirnov M.A., Lavrov A.V., Shevtsov V.G. National interests: priorities and security, 14, 48-61 (2018).

2. Kryazhkov. V.M., Godzhaev Z.A., Shevtsov V.G., Lavrov A.V. Rural mechanic, 9, 35 (2015).

3. Kryhkov V.M., Godzhaev Z.A., Shevtsov V.G., Gurylev G.S., Lavrov A.V. SAE, 14, 48-61 (2016).

4. Shevtsov V., Lavrov A., Izmailov A. and Lobachevskii Y. Formation of SAE, 14, 4861 (2015).

5. Production of automobile, tractor and agricultural machinery and components for it by manufacturers of Russia and other CIS countries // Analytical review / JSC "ASMHolding". -2009, 2010, 2011, 2012, 2013, 2014, 2015, 2016, 2017, 12 (2019).

6. Godzhaev Z.A., Lavrov A.V., Shevtsov V.G., Zubina V.A. Izvestiya MSTU «MAMI». 1 (43). , 35-41 (2020).

7. Izmailov A.Yu., Kryazhkov V.M., Antyshev N.M. and others. Concept of modernization of the Russian agricultural tractor fleet for the period up to 2020. -M .: VIM, 2013.-84 p.

8. https://new.fips.ru. 